\title{
High prevalence of musculoskeletal symptoms and injuries in third space endoscopists: an international multicenter survey*
}

(9) $\odot \ominus$

\author{
Authors \\ Samuel Han, Hazem T. Hammad, Mihir S. Wagh
}

Institution

Division of Gastroenterology and Hepatology, University of Colorado School of Medicine, Aurora, Colorado, United States

submitted 10.6 .2020

accepted after revision 20.7.2020

Bibliography

Endoscopy International Open 2020; 08: E1481-E1486

DOI 10.1055/a-1236-3379

ISSN 2364-3722

(c) 2020. The Author(s).

This is an open access article published by Thieme under the terms of the Creative Commons Attribution-NonDerivative-NonCommercial License, permitting copying and reproduction so long as the original work is given appropriate credit. Contents may not be used for commecial purposes, or adapted, remixed, transformed or built upon. (https://creativecommons.org/licenses/by-nc-nd/4.0/)

\section{Corresponding author}

Mihir S. Wagh, MD, FACG, FASGE, Interventional Endoscopy, Division of Gastroenterology, University of Colorado-Denver, 1635 Aurora Court, F735, Aurora, CO 80045, USA

Fax: +1-720-848-2749

mihir.wagh@cuanschutz.edu

Supplementary material is available under https://doi.org/10.1055/a-1236-3379

\section{ABSTRACT}

Background and study aims Third space endoscopy (TSE), including per-oral endoscopic myotomy and endoscopic submucosal dissection, is technically challenging and physically demanding. The aim of this study was to assess the prevalence and types of musculoskeletal symptoms and injuries (MSI) in third space endoscopists and its impact on clinical practice.

Materials, Patients and methods A 22-item survey measuring endoscopist characteristics, procedure volumes, MSI, and its effect on clinical practice was distributed to endoscopists practicing TSE. Descriptive statistics were used to depict MSI. Logistic regression was used to identify predictors for MSI related to TSE.

Results The survey was completed by 45 of 110 endoscopists $(40.9 \%)$ who received the survey, representing 10 countries across four continents. Thirty-one (69\%) endoscopists reported current MSI with $71 \%(n=22 / 31)$ believing these began after starting TSE, and $48.9 \%$ (22/45) reporting more symptoms after TSE compared to endoscopic ultrasound/endoscopic retrograde cholangiopancreatography. Common MSI included the shoulders (42.2\%), back (37.8\%), neck (33.3\%), and wrist (24.4\%). Lower extremity MSI were also reported with foot symptoms (11.1\%) being most common. A minority required disability (2.2\%), change in endoscopy scheduling $(6.7 \%)$ or surgery $(2.2 \%)$. Only $15.6 \%$ of endoscopists had received prior ergonomics training. Logistic regression revealed no significant predictors for MSI.

Conclusions Over two-thirds of endoscopists performing TSE suffer from MSI, with many reporting onset of their symptoms after starting TSE in their practice. Further studies are needed to understand and reduce the risk of MSI in TSE given the growing demand for these procedures and the potential long-term impact of this occupational hazard.
* Meeting presentations: This study was accepted for oral presentation in the ASGE Presidential Plenary Session at Digestive Disease Week 2020

\section{Introduction}

The physical strain of endoscopy has garnered considerable attention as an occupational hazard in the field of gastroenterology where performing endoscopy accounts for a significant 
proportion of clinical practice [1,2]. With nearly 11 million colonoscopies and over 6 million upper endoscopies performed in the United States on an annual basis, endoscopic procedure volume remains high, which represents one of the greatest risk factors for developing an endoscopy-related injury [3,4]. These injuries can result in time lost from work, decreased productivity, modification of clinical practices, and even long-term disability, not to mention the possibility of shortening the endoscopist's career or decreasing their quality of life [4-6].

Most prior studies have focused on examining the prevalence and risk factors for musculoskeletal symptoms and injuries (MSI) in endoscopists performing upper endoscopies and colonoscopies with few studies examining the toll of performing advanced procedures such as endoscopic retrograde cholangiopancreatography (ERCP) and endoscopic ultrasound (EUS) [4, 5,7-9]. Repetitive motions, sustained unnatural positions, awkward postures, and increased forces on the body are believed to drive the development of injuries related to endoscopy and colonoscopy [10]. Along these same lines, the growing number of third space endoscopists performing complex procedures such as endoscopic submucosal dissection (ESD) and per-oral endoscopic myotomy (POEM), where long procedure times involving awkward hand, wrist, and neck postures are common, are potentially prone to developing injuries.

In response to the high prevalence of injuries related to endoscopy, the ergonomics of endoscopy takes even greater importance. By focusing on understanding the interplay between the endoscopist, the endoscope, and the work environment, the study of ergonomics seeks to develop strategies to reduce the risk of injury [11]. With this context in mind, we performed a survey study assessing MSI in endoscopists performing third space endoscopy (TSE) to better understand the ergonomics of TSE.

\section{Materials and methods}

\section{Study design}

This was a survey study conducted from October to December 2019 on third space endoscopists across the world. Only endoscopists who currently practice TSE were asked to complete the survey. This study received approval from the Colorado Multiple Institutional Review Board. Survey response implied informed consent.

\section{Aims and definitions}

The aim of this study was to assess the prevalence and types of MSI in third space endoscopists and its impact on clinical practice. Impact of MSI on clinical practice was defined as the downstream effects of MSI including need for disability or time off from work, change in endoscopy schedule, treatment(s) needed, and ergonomic interventions during endoscopy. A secondary aim was to identify risk factors associated with the development of MSI in third space endoscopists.

\section{Survey instrument}

The survey (Supplement) was a 22-item, self-administered survey developed by two endoscopists (MSW and SH) using REDCap [12]. The survey instrument underwent two iterations before its final version and incorporated several key components: endoscopist characteristics, endoscopist experience, MSI, treatments, and prevention measures. Endoscopist experience included current TSE and overall case volumes broken down by type of procedure. MSI included location of injuries and their downstream effects such as need for disability or time off from work, and treatment(s) needed.

\section{Survey administration}

The survey was distributed via email with a link to the survey on REDCap hosted by the University of Colorado. A reminder email was sent to all participants 2 weeks after the initial email. Surveys were also distributed in paper format at national and international conferences and endoscopy courses, and at societal committee meetings. All responses were anonymous to reduce the possibility of response bias.

\section{Statistical analysis}

Descriptive statistics were utilized to describe endoscopist characteristics and experience, musculoskeletal symptoms and injuries (MSI), and prevention/treatment measures. Logistic regression was performed to identify risk factors for having MSI definitely or possibly related to TSE. Variables significant at $P<$ 0.05 on univariate analysis were incorporated into a multivariate logistic regression. $P<0.05$ was considered to be significant. All analysis was performed using STATA 15.1 (StataCorp, College Station, Texas, United States).

\section{Results}

\section{Survey participants}

The survey was sent to 110 endoscopists who practice TSE, of which 45 (40.9\%) completed the survey. Respondents (mean age of 45.6 [SD 7.2] years, $97.8 \%$ male) represented 10 countries spanning four continents ( $\triangleright$ Table 1 ). Participants had a mean experience of 12.3 (SD 8.9) years in interventional endoscopy with a mean experience of 5.8 (SD 3.1) years performing TSE. Survey respondents performed a mean of 9.5 (SD 10.1) ESDs/month in addition to a mean of 8.2 (SD 9.6) endoscopic myotomies/month. The mean total procedural volume/week was 33.8 (SD 14.6) procedures and the mean total TSE volume over the course of a career was 460.2 (SD 642.6, median 180) procedures.

\section{Musculoskeletal Injuries}

Over two-thirds ( $n=31,69 \%$ ) of participating endoscopists reported current musculoskeletal symptoms or injuries. $71 \%$ of endoscopists who reported MSI believed that these symptoms or injuries began after starting TSE in their practice. Overall, $48.9 \%$ of participants reported more MSI with TSE compared to ERCP/EUS. A minority of endoscopists missed work (2.2\%), reduced their clinical schedule $(6.7 \%)$ or required temporary 
- Table 1 Baseline characteristics of third space endoscopists.

\begin{tabular}{|c|c|}
\hline Variable & Mean (SD) or N (\%) \\
\hline - Age & $45.6(7.2)$ \\
\hline - Male sex & $44(97.8 \%)$ \\
\hline - Right-handed & $37(82.2 \%)$ \\
\hline - Surgical glove size & $7.6(0.5)$ \\
\hline \multicolumn{2}{|l|}{ Continent of practice } \\
\hline - North America & $31(68.9 \%)$ \\
\hline - South America & $1(2.2 \%)$ \\
\hline " Europe & $5(11.1 \%)$ \\
\hline - Asia & $8(17.8 \%)$ \\
\hline Years of practicing interventional endoscopy & $12.3(8.9)$ \\
\hline Years of practicing third space endoscopy & $5.8(3.1)$ \\
\hline Number of ESDs performed/month & $\begin{array}{l}9.5(10.1) \\
\text { Median: } 6 \\
\text { (Range: } 1-43)\end{array}$ \\
\hline $\begin{array}{l}\text { Number of endoscopic myotomies per- } \\
\text { formed/month (POEM, G-POEM, Z-POEM, } \\
\text { D-POEM) }\end{array}$ & $\begin{array}{l}8.2(9.6) \\
\text { Median: } 5 \\
\text { (Range: } 0-43)\end{array}$ \\
\hline $\begin{array}{l}\text { Number of full-thickness resections per- } \\
\text { formed/month }\end{array}$ & $\begin{array}{l}4.8(2.2) \\
\text { Median: } 1 \\
\text { (Range: } 0-10)\end{array}$ \\
\hline $\begin{array}{l}\text { Total number of third space endoscopies } \\
\text { performed in career }\end{array}$ & $\begin{array}{l}460.2(642.6) \\
\text { Median: } 180 \\
\text { (Range: } 18-2500)\end{array}$ \\
\hline Number of all endoscopies performed/week & $33.8(14.6)$ \\
\hline Currently performing ERCP/EUS & $40(88.9 \%)$ \\
\hline Regular exercise & $41(91.1 \%)$ \\
\hline Hours spent exercising/week & $2.9(1.8)$ \\
\hline \multicolumn{2}{|c|}{$\begin{array}{l}\text { ESD, endoscopic submucosal dissection; POEM, per-oral endoscopic myot- } \\
\text { omy; G-POEM, gastric per-oral endoscopic myotomy; Z-POEM, per-oral } \\
\text { endoscopic myotomy for Zenker's diverticulum; D-POEM, per-oral endo- } \\
\text { scopic myotomy for esophageal diverticula; ERCP, endoscopic retrograde } \\
\text { cholangiopancreatography; EUS, endoscopic ultrasound }\end{array}$} \\
\hline
\end{tabular}

disability $(2.2 \%)$ due to MSI related to TSE. One endoscopist $(2.2 \%)$ required surgery for MSI.

The most common locations for symptoms/injuries included the shoulders (42.2\%), back (37.8\%), neck (33.3\%), and wrist (24.4\%) ( $\triangleright$ Table 2). In terms of laterality, the right shoulder $(33.3 \%)$ was more often involved than the left $(13.3 \%)$ while the left thumb $(13.3 \%)$ was more commonly affected than the right (4.4\%). The upper back (22.2\%) was slightly more affected than the lower back (17.8\%) as was the right hip (6.7\%) compared to the left hip (2.2\%).

In regards to endoscopist level of physical activity, 41 (91.1\%) endoscopists exercised regularly and spent a mean of 2.9 (SD 1.8) hours/week exercising. A minority $(n=7)$ had ever received training in ergonomics and $37.8 \%(n=17)$ performed an "ergonomic time-out" prior to starting a TSE case with the
- Table2 Musculoskeletal symptoms/injuries, treatment, and prevention.

\begin{tabular}{|c|c|}
\hline Variable & $\mathbf{N}(\%)$ \\
\hline \multicolumn{2}{|c|}{ Location of symptoms and injuries } \\
\hline - Neck & $15(33.3 \%)$ \\
\hline - Shoulder & 19 (42.2\%)-Right (33.3\%), Left (13.3\%) \\
\hline - Back & 17 (37.8\%)-Upper (22.2\%), Lower (17.8\%) \\
\hline - Elbow and forearm & 2 (4.4\%)-Right (2.2\%), Left (2.2\%) \\
\hline - Wrist & 11 (24.4\%)-Right (15.6\%), Left (15.6\%) \\
\hline - Hand & $8(17.8 \%)$-Right (11.1\%), Left (11.5\%) \\
\hline - Thumb & 7 (15.6\%)-Right (4.4\%), Left (13.3\%) \\
\hline - Hip & 4 (8.9\%)-Right (6.7\%), Left (2.2\%) \\
\hline - Leg & 2 (4.4\%)-Right (2.2\%), Left (4.4\%) \\
\hline - Knee & 3 (6.7\%)-Right (4.4\%), Left (2.2\%) \\
\hline - Foot & 5 (11.1\%)-Right (6.7\%), Left (6.7\%) \\
\hline \multicolumn{2}{|c|}{ Treatments for musculoskeletal symptoms/injuries } \\
\hline - Pain medications & $9(20 \%)$ \\
\hline $\begin{array}{l}\text { Anti-inflammatory } \\
\text { medications }\end{array}$ & $22(48.9 \%)$ \\
\hline - Splints/braces & $5(11.1 \%)$ \\
\hline - Injections & $1(2.2 \%)$ \\
\hline $\begin{array}{l}\text { - Chiropractic } \\
\text { adjustment }\end{array}$ & $3(6.7 \%)$ \\
\hline - Massage therapy & $12(26.7 \%)$ \\
\hline - Physical therapy & $1(2.2 \%)$ \\
\hline - Surgery & $1(2.2 \%)$ \\
\hline Ergonomics training & $7(15.6 \%)$ \\
\hline $\begin{array}{l}\text { Ergonomic time-out } \\
\text { prior to case }\end{array}$ & $17(37.8 \%)$ \\
\hline $\begin{array}{l}\text { Monitor position/ } \\
\text { height }\end{array}$ & $16(35.6 \%)$ \\
\hline Bed position/height & $12(26.7 \%)$ \\
\hline Floor mats & $4(8.9 \%)$ \\
\hline Food pedal position & $14(31.1 \%)$ \\
\hline $\begin{array}{l}\text { Micro-breaks during } \\
\text { third space endoscopy }\end{array}$ & $20(44.4 \%)$ \\
\hline
\end{tabular}

most common component being ensuring proper monitor position/height (35.6\%). Nearly half $(44.4 \%, \mathrm{n}=20)$ of the endoscopists reported taking micro-breaks during a TSE case. The most common treatments for MSI included anti-inflammatory medications (48.9\%), massage therapy (26.7\%) and taking pain medications (20\%). 
- Table 3 Risk factors for musculoskeletal symptoms/injuries related to third space endoscopy.

\begin{tabular}{|c|c|c|}
\hline Variable & Univariate odds ratio & $P$ value \\
\hline - Age & 1.04 (95\% Cl: 0.95-1.14) & 0.43 \\
\hline - Surgical glove size & 0.96 (95\% Cl: $0.28-3.3)$ & 0.95 \\
\hline - Right-handedness & 1.42 (95\% Cl: 0.29-6.9) & 0.67 \\
\hline - Years of practicing interventional endoscopy & 0.99 (95\% Cl: 0.92-1.06) & 0.79 \\
\hline - Years of practicing third space endoscopy & 1.1 (95\% Cl: 0.89-1.36) & 0.39 \\
\hline - Number of ESDs performed/month & $1.02(95 \% \mathrm{Cl}: 0.95-1.1)$ & 0.55 \\
\hline - Number of endoscopic myotomies performed/month (POEM, G-POEM, Z-POEM, D-POEM) & 1.04 (95\% Cl: 0.96-1.13) & 0.37 \\
\hline - Number of full-thickness resections performed/month & 1.09 (95\% Cl: 0.78-1.5) & 0.64 \\
\hline - Total number of third space endoscopies performed in career & 1.0 (95\% Cl: 0.99-1) & 0.55 \\
\hline - Number of endoscopies performed/week & 1.01 (95\% Cl: 0.97-1.06) & 0.67 \\
\hline - Currently performing ERCP/EUS & $0.52(95 \% \mathrm{Cl}: 0.05-5.1)$ & 0.58 \\
\hline - Hours spent exercising/week & 0.8 (95\% Cl: $0.56-1.15)$ & 0.23 \\
\hline - Micro-breaks during third space endoscopy & $0.72(95 \% \mathrm{Cl}: 0.2-2.57)$ & 0.62 \\
\hline
\end{tabular}

\section{Factors associated with TSE-related musculoskeletal symptoms/injuries}

On univariate logistic regression, there were no variables significantly associated with development of MSI ( $>$ Table 3 ). Variables previously found to be associated with development of musculoskeletal injuries in endoscopists such as procedure volume (OR: 1.01, $95 \% \mathrm{Cl}$ : 0.96-1.06), glove size (OR: 0.96, $95 \%$ Cl: $0.28-3.3$ ) or age (OR: $1.04,95 \% \mathrm{Cl}: 0.95-1.14)$ were not significantly associated with development of musculoskeletal issues in this study. No variables met pre-determined criteria for inclusion in a multivariate logistic regression.

\section{Discussion}

The effect of musculoskeletal pain and injuries on the workforce continues to draw considerable attention given the potential ramifications on cost, career length, and quality of life. In the field of gastroenterology, a growing body of literature suggests that performing endoscopy is associated with relatively high rates of musculoskeletal injuries. Given the high volume of endoscopy and the ever-expanding role of endoscopy worldwide, the physical toll of endoscopy carries particular importance especially as many gastroenterologists will have careers spanning 20 to 30 years and injuries are being reported as early as during fellowship $[7,13]$. Within this context, we decided to examine the prevalence of MSI in endoscopists who perform TSE, a particularly challenging and taxing niche of endoscopy that has evolved over the past decade.

Previously published studies have assessed MSI in endoscopists performing general endoscopy (upper endoscopy and colonoscopy) and in those performing ERCP. In the largest sur- vey done examining endoscopy-related musculoskeletal injuries, which targeted members of the American Society for Gastrointestinal Endoscopy (ASGE), 53\% of endoscopists had reported injuries [4]. Similarly, in a study involving 190 endoscopists in Japan, $43 \%$ reported musculoskeletal pain [8]. Overall, however, rates of musculoskeletal issues vary widely among endoscopists, ranging from $29 \%$ to $89 \%$ [6, 14]. In our study, 69 $\%$ of third space endoscopists reported MSI. The prevalence of injuries in our study is perhaps most similar to another subgroup survey where $67 \%$ of endoscopists who perform ERCP in Canada reported at least one musculoskeletal complaint, although in our study, nearly half of the endoscopists reported more symptoms related to TSE compared to performing ERCP and EUS [9]. Regardless, a high proportion of third space endoscopists described MSI, which certainly warrants monitoring given the increasing interest in these endoscopic techniques.

Prior studies focusing primarily on upper endoscopy and colonoscopy have described the neck, upper and lower back, thumb, and wrists as the primary sites of pain $[4-6,8,15]$. Similarly, in our study, the shoulders, back, neck, and wrists were the most common sites of musculoskeletal discomfort. Interestingly, third space endoscopists also reported hips, legs, knees, and feet as locations of musculoskeletal symptoms. While it is unclear as to how exactly TSE affects the lower body, this may be related to constantly pressing the electrocautery foot pedal, pivoting the foot to switch between cut and coagulation modes, or stepping on the water jet pedal for submucosal injection, which can often cause unbalanced shifting of weight onto one foot or the other for long periods of time. Similar to certain joint-injury syndromes such as DeQuervain's te- 
nosynovitis (colonoscopist's thumb) or biliary endoscopist's knuckle that have become associated with certain types of endoscopy, monitoring the unique physical stresses of TSE on the body remains critical as the field grows $[15,16]$.

As MSI become more recognized in the field of endoscopy, studies have begun to examine the physical mechanics at play in performing endoscopy. In a study measuring forces exerted during colonoscopy, right-thumb peak pinch forces were found to be greatest during left and right colon insertion [17]. Furthermore, the wrist joint range of motion has been found to be at extreme levels for up to $30 \%$ of the duration of a colonoscopy, which is particularly applicable to TSE where long periods of non-neutral positions and posture may be required for certain parts of the dissection [18]. In TSE procedures such as POEM and ESD, biomechanical forces may be exerted throughout the entire body, such as when the endoscope is being maintained in unnatural body positions repeatedly or persistently during the procedure and in the aforementioned situation where the endoscopist is constantly stepping on different foot pedals. Given that overuse, repetitive motions, and awkward positions have been shown to cause strain, micro-trauma and eventually injuries, we are likely seeing the early symptoms of the physical toll of performing TSE and more studies will be needed to determine the biophysics involved in these procedures [19].

In examining the impact of MSI on third space endoscopists, only a small proportion of participating endoscopists required time off from work or temporary disability due to their symptoms. A prior Korean study had demonstrated that $16 \%$ of endoscopists had modified their clinical practice due to musculoskeletal pain, and a study from the Mayo Clinic reported $13 \%$ of gastroenterologists/hepatologists missing work with $2.8 \%$ requiring long-term disability. The lower rates seen in our study may reflect the relatively young history of TSE since there is an association between injury and length of time in practice [4]. In regards to treatment, nearly half of participating endoscopists used anti-inflammatory medications with greater than $25 \%$ using massage therapy and $20 \%$ using pain medications. These are in line with prior studies, and future studies should focus on identifying the most effective treatments given the high prevalence of injuries [4]. Perhaps the most effective treatment rests in prevention of these injuries. The study of ergonomics, in particular, has gained particular attention within this realm in an effort to understand how workplace adjustments can be made to prevent these injuries. A small minority of endoscopists in our study had received any ergonomics training and less than half of endoscopists followed societal ergonomic recommendations such as adjusting monitor height, bed height or taking breaks [1]. Therefore, a clear opportunity for injury prevention remains in ergonomics education and implementation, and further research is needed to identify optimal prevention methods.

Another way to improve the safety and efficiency of these procedures (and therefore potentially make it less demanding for the endoscopist) is to improve the tools used for TSE. A major step would be to drastically change the physical structure of the endoscope which has not changed despite the emergence of newer endoscopic procedures which are considerably differ- ent from diagnostic upper endoscopies and colonoscopies, for which the endoscope was originally designed. In addition, modifications to the endoscope and endoscopic accessories such as multibending endoscopes, traction devices, and the recently available double balloon endoluminal interventional platform could also improve the efficiency of these rather long procedures and help decrease the risk of potential injury associated with them [20-22].

Several limitations of this study warrant further description. In addition to the inherent limitations of a self-reported survey study, participation and sample bias may have influenced our results given that the majority of responses came from US endoscopists despite invitations to many endoscopists from around the world. Along these lines it may be that more endoscopists with MSI responded readily to the survey than those without musculoskeletal symptoms, thereby introducing bias. Furthermore, since this is a survey study, we do not have objective data showing that endoscopists did not have MSI prior to starting TSE. All responses are therefore subjective and the attribution of MSI to TSE may be prone to recall and recency bias. While the sample size is relatively small, our participation rate was relatively high, and the small sample size is likely a reflection of the small number endoscopists who perform TSE. Nevertheless, the small sample size hinders the ability to perform a multivariable analysis to analyze risk factors for injuries. We also acknowledge the limitation that responses were subjective without objective confirmation of the type and severity of the injury, physical mechanics involved in TSE, and without direct comparison with non-TSE procedures. Also, the majority of our respondents were male $(97.8 \%$ ) in whom the extent and pattern of MSI may be very different from female endoscopists. In addition to potentially having smaller hands, women may have less force generation ability and are therefore more vulnerable to MSI from endoscopy $[11,17]$. This could not be assessed in our study. Another limitation to consider is regional and cultural bias where MSI may or may not be considered significant based on an endoscopist's social and cultural background, leading to underreporting or overreporting in endoscopists from different parts of the world. Lastly, this study did not distinguish between different TSE procedures such as ESD, POEM, or G-POEM, which will require further investigation.

\section{Conclusion}

In conclusion, MSIs are highly prevalent in endoscopists performing TSE. While the risk factors for development of these injuries remain unclear, the long procedure times, repetitive motions, and sustained awkward positions associated with TSE may add another degree of complexity to understanding the biomechanics of performing endoscopy. Objective evaluation of endoscopist postures, forces generated, and potential trauma sustained during TSE will be crucial. As the field of TSE continues to grow and expand, future studies will be needed to help prevent and treat injuries, educate endoscopists, and improve endoscopy facilities with the goal of delivering optimal patient care while preserving the health of endoscopists worldwide. 


\section{Competing interests}

Dr. Wagh is a consultant for Olympus, Boston Scientific, and Medtronic. Dr. Hammad is a consultant for Olympus, Medtronic, and Cook Medical.

\section{References}

[1] Pedrosa MC, Farraye FA, Shergill AK et al. Minimizing occupational hazards in endoscopy: personal protective equipment, radiation safety, and ergonomics. Gastrointest Endosc 2010; 72: 227-235

[2] Cohen LB, Wecsler JS, Gaetano JN et al. Endoscopic sedation in the United States: results from a nationwide survey. Am J Gastroenterol 2006; 101: 967-974

[3] Peery AF, Crockett SD, Murphy CC et al. Burden and cost of gastrointestinal, liver, and pancreatic diseases in the United States: update 2018. Gastroenterology 2019; 156: 254-272.e211

[4] Ridtitid W, Cote GA, Leung W et al. Prevalence and risk factors for musculoskeletal injuries related to endoscopy. Gastrointest Endosc 2015; 81: 294-302.e294

[5] Hansel SL, Crowell MD, Pardi DS et al. Prevalence and impact of musculoskeletal injury among endoscopists: a controlled pilot study. J Clin Gastroenterol 2009; 43: 399-404

[6] Byun YH, Lee JH, Park MK et al. Procedure-related musculoskeletal symptoms in gastrointestinal endoscopists in Korea. World J Gastroenterol 2008; 14: 4359-4364

[7] Villa E, Attar B, Trick W et al. Endoscopy-related musculoskeletal injuries in gastroenterology fellows. Endosc Int Open 2019; 7: E808-E812

[8] Kuwabara T, Urabe Y, Hiyama T et al. Prevalence and impact of musculoskeletal pain in Japanese gastrointestinal endoscopists: a controlled study. World J Gastroenterol 2011; 17: 1488-1493

[9] O'Sullivan S, Bridge G, Ponich T. Musculoskeletal injuries among ERCP endoscopists in Canada. Can J Gastroenterol 2002; 16: 369-374

[10] Shergill AK, McQuaid KR, Rempel D. Ergonomics and GI endoscopy. Gastrointest Endosc 2009; 70: 145-153
[11] Shergill AK, McQuaid KR. Ergonomic endoscopy: An oxymoron or realistic goal? Gastrointest Endosc 2019; 90: 966-970

[12] Harris PA, Taylor R, Thielke R et al. Research electronic data capture (REDCap)-a metadata-driven methodology and workflow process for providing translational research informatics support. J Biomed Inform 2009; 42: 377-381

[13] Austin K, Schoenberger $\mathrm{H}$, Sesto $\mathrm{M}$ et al. Musculoskeletal injuries are commonly reported among gastroenterology trainees: results of a national survey. Digest Dis Sci 2019; 64: 1439-1447

[14] Harvin G. Review of musculoskeletal injuries and prevention in the endoscopy practitioner. J Clin Gastroenterol 2014; 48: 590-594

[15] Buschbacher R. Overuse syndromes among endoscopists. Endoscopy 1994; 26: 539-544

[16] Cappell MS. Colonoscopist's thumb: DeQuervains's syndrome (tenosynovitis of the left thumb) associated with overuse during endoscopy. Gastrointest Endosc 2006; 64: 841-843

[17] Shergill AK, Asundi KR, Barr A et al. Pinch force and forearm-muscle load during routine colonoscopy: a pilot study. Gastrointest Endosc 2009; 69: 142-146

[18] Mohankumar D, Garner H, Ruff K et al. Characterization of right wrist posture during simulated colonoscopy: an application of kinematic analysis to the study of endoscopic maneuvers. Gastrointest Endosc 2014; 79: 480-489

[19] Rempel DM, Harrison RJ, Barnhart S. Work-related cumulative trauma disorders of the upper extremity. JAMA 1992; 267: 838-842

[20] Matsumoto K, Konuma H, Ueyama H et al. Multibending scope use for reduction of perforation risks in endoscopic submucosal dissection. Minim Invasive Ther Allied Technol 2020: doi:10.1080/13645706. 2019.1688352

[21] Abe S, Wu SYS, Ego M et al. Efficacy of current traction techniques for endoscopic submucosal dissection. Gut Liver 2020: doi:10.5009/ gnl19266

[22] Sharma S, Momose K, Hara $\mathrm{H}$ et al. Facilitating endoscopic submucosal dissection: double balloon endolumenal platform significantly improves dissection time compared with conventional technique (with video). Surg Endosc 2019; 33: 315-321 